\title{
Déficits ambientais hídricos na Orla Norte de Porto Seguro-Bahia
}

\author{
Elissandro dos Santos Santana \\ Licenciado em letras - língua estrangeira moderna - espanhol \\ Especialista em Sustentabilidade, Desenvolvimento e Gestão de Projetos Sociais \\ Especialista em Linguística e Ensino de Línguas \\ Especialista em Metodologia do Ensino de Língua Espanhola \\ Especialista em Gestão Educacional \\ Membro do Conselho Editorial da Revista Letrando \\ Colaborador e colunista de sustentabilidade e de meio ambiente do Portal Desacato \\ $\triangle$ lissandrosantana@hotmail.com
}

Recebido em 8 de julho de 2016

Aceito em 29 de novembro de 2016

\section{Resumo:}

A cultura relacional da sociedade porto-segurense com os rios da cidade alicerça-se em bases insustentáveis e, aliado a tal fator, há os impactos indiretos por trás do turismo na região, desencadeadores de déficits ambientais no capital natural hídrico do município. Diante disso, este artigo desponta como uma reflexão em torno da situação ambiental de alguns rios, riachos e cursos de água do perímetro localizado na Orla Norte de Porto Seguro, importante polo turístico baiano e, consequentemente, brasileiro.

Palavras-chave: Sociedade; Porto-segurense; Déficits ambientais; Rios; Orla Norte.

\section{The environmental status of the rivers of the North Rim of Porto Seguro-Bahia}

\begin{abstract}
:
The relational culture of society porto-segurense with rivers city is founded on unsustainable foundations and, allied to this factor, there are indirect impacts behind tourism in the region, triggers environmental deficits in natural capital water municipality. At that, this article stands out as an analysis of the environmental situation of some rivers, streams and waterways located on the perimeter of the northern edge of Porto Seguro, Bahia major tourist destination and consequently, Brazilian.
\end{abstract}

Keywords: Society; Porto-segurense; Environmental deficits; Rivers; North Rim.

\section{La situación ambiental de los ríos de la Costanera Norte de Porto Seguro-Bahia}

\begin{abstract}
Resumen:
La cultura relacional de la sociedad porto-segurense con los ríos de la ciudad está fundada sobre bases insostenibles y, aliadas a este factor, hay los impactos indirectos por detrás del turismo en la región, disparadores de déficits ambientales en el capital natural del agua del municipio. Ante eso, este artículo despunta como un análisis de la situación ambiental de algunos ríos, arroyos y cursos
\end{abstract}


de agua ubicados en el perímetro del borde del norte de Porto Seguro, importante polo turístico de Bahía y, en consecuencia, brasileño.

Palabras clave: Sociedad; Porto-segurense; Déficits ambientales; Ríos; Costanera del Norte.

\section{INTRODUÇÃO}

O interesse por estudar o quadro ambiental hídrico do município de Porto Seguro surgiu a partir da empiria do contato com a cultura relacional do descaso político-social da cidade com os rios.

O problema ambiental no tocante à situação dos recursos hídricos do município, em especial, dos rios e riachos do perímetro da Orla Norte ${ }^{1}$, é crítico e, por isso, demanda estudos científicos amplos em campos diversos, partindo-se de questões como poluição, desmatamento de matas ciliares, visibilidade da água, Psicologia ambiental (levando-se em consideração que já existem estudos científicos que comprovam os efeitos benéficos que a natureza propicia ao/no ser humano quando este entra em contato direto com áreas naturais preservadas e conservadas), qualidade da água a partir da análise dos elementos macro-micro-biológicos, vetores de poluição da água e outros elementos.

Os déficits ambientais verificados nos rios Jardim, dos Mangues, Mundaí, São Francisco e da Vila resultam de relações político-sociais insustentáveis e a reflexão que será apresentada ao longo deste trabalho servirá de ponto de partida para outros olhares e atuação pública no que tange às mitigações ambientais necessárias para a recuperação, conservação e preservação do capital natural hídrico.

Diante do fato de que o principal problema desencadeador de déficits ambientais nos rios do perímetro analisado está na relação da sociedade com os rios e que o turismo, até certo ponto, também contribui para que a situação se agrave, esse trabalho desponta mais como uma reflexão do que, propriamente, como uma análise científica em torno da situação ambiental hídrica na Orla Norte. Isso se dá devido ao fato de que não foi possível fazer uma análise científica da água, haja vista que a pesquisa fora desenvolvida sem apoio financeiro, portanto, inviabilizando-se exames de qualidade da água para verificar os níveis de contaminação, por exemplo, mas, diante do fato de que a poluição se dá de forma visível, foi possível fazer uma reflexão de cunho empírico, a partir do mapeamento da presença de resíduos sólidos encontrados às margens de quase todos os rios visitados durante períodos específicos ao longo

\footnotetext{
${ }^{1} \mathrm{O}$ artigo "A situação ambiental dos rios da Orla Norte de Porto Seguro-Bahia" foi publicado, inicialmente, no Portal Desacato e, nessa ocasião, ampliado para publicação na Revista SUSTINERE.
} 
dos anos de 2014 e 2015.

\title{
RELAÇÕES SOCIAIS INSUSTENTÁVEIS COM OS RIOS E INÉRCIA PÚBLICA EM
}

\section{PORTO SEGURO}

Miller Jr. (2012), ao discorrer sobre água e poluição, em um estudo de caso sobre conflitos pela água no Oriente Médio, traz à baila uma informação que pode ser aplicada à experiência de Porto Seguro. Ele pontua o seguinte: "Para muitos analistas, a escassez de água existente em diversas partes do planeta, aliada a questões relacionadas à perda de biodiversidade e mudança climática, são os três problemas ambientais mais graves que o mundo encara neste século".

No Brasil, além da cultura de descaso com os rios e outros capitais naturais, situação essa que ocorre em Porto Seguro, uma das cidades históricas mais importantes do país, há a ideia equivocada de que pelo país ser a nação com maior reserva hídrica, pode-se usar a água sem grandes preocupações. Acerca desse imaginário de abundância, é imprescindível refletir sobre o que pontua Trigueiro (2012):

\begin{abstract}
Nenhum outro país do mundo tem tanta água. Somos uma nação generosamente irrigada por 12 mil rios e córregos e que detém, na Bacia do rio Amazonas, a maior concentração de água doce do planeta. Mas o que é abundante na região norte está se tornando rapidamente escasso no resto do país. Esse é o mapa da vergonha. Segundo o Instituto Brasileiro de Geografia e Estatística (IBGE), multiplica-se nas áreas mais populosas do país o lançamento de esgoto sem tratamento. Dá para entender por que a falta de saneamento é um dos maiores problemas do país (TRIGUEIRO, 2012).
\end{abstract}

Em Porto Seguro, ao longo de anos, vem-se explorando e usando os rios de uma forma insustentável, o que causou o comprometimento ambiental desses recursos hídricos e pode chegar a um ponto em que não será possível recuperação ambiental.

O quadro fica ainda pior diante do fato de que a sociedade visualiza o problema, mas não cobra das gestões públicas locais soluções ambientais. Essa não cobrança faz parte, talvez, de uma cultura de perda que gerou, ao longo de anos, o desligamento da sociedade local com a natureza. Esse mesmo comportamento se repete em outras partes do Brasil e do Planeta e, por isso, é importante trazer o problema para discussão.

A partir desse desligamento do homem local com o meio-ambiente, é preciso pensar 
formas de conscientizar e sensibilizar a população local para os riscos da relação de exploração e de depredação dos recursos hídricos, mostrando-se que essas insustentabilidades relacionais podem provocar problemas ambientais que levarão à escassez de água no município.

Acerca dessa cultura de desligamento dos construtos sociais e, principalmente, políticos, no que concerne à situação hídrica e ambiental em geral no município, é importante recorrer ao que pontua Boff (2015):

O ser humano se isolou da natureza, quebrou os laços de pertença à comunidade de vida, esquecido da teia das interdependências e da sinergia de todos os elementos naturais e cósmicos para que emergisse no processo evolucionário. Ele se encaramujou sobre si mesmo. Destruiu os símbolos de sua natureza espiritual... e mergulhou num incomensurável vazio, desenraizado da natureza e entregue à sua solidão. Daí nasce o pessimismo, a amargura e a náusea, que são a falta de alegria de viver (BOFF, 2015).

A presença de resíduos nos rios é reveladora da noção ultrapassada de que o rio serviria como meio para levar para distante tudo aquilo que não presta, portanto, ao jogar o lixo no rio, muitos fazem a partir dessa ótica. Diante desse valor equivocado, é necessário tocar a consciência política da sociedade, mostrando o que apresenta Miller Jr. (2012) acerca da importância da água:

\begin{abstract}
As reservas de água doce do planeta são continuamente coletadas, purificadas, recicladas e distribuídas no ciclo hidrológico movido pelo sol. Esse magnífico sistema de purificação e reciclagem da água funciona bem, desde que não sobrecarreguemos os sistemas de água com resíduos não degradáveis, ou de degradação lenta, ou retiremos água de fontes subterrâneas mais rápido do que é reposta. Em algumas partes do mundo, estamos fazendo ambas as coisas (MILLER JR. 2012).
\end{abstract}

O que ocorre em Porto Seguro no que tange à relação da sociedade com os rios, prova que não há uma preocupação com os recursos hídricos da cidade. Talvez, essa concepção esteja atrelada a um imaginário obsoleto, fruto dos primeiros processos de industrialização e de exploração dos recursos naturais na indústria de fabricação de bens materiais e serviços, de que os recursos naturais são infinitos.

A sociedade porto-segurense precisa despertar para os déficits ambientais que já ocorrem na cidade. Como exemplo de um déficit ambiental hídrico na região, pode-se recorrer ao que afirma Santana (2016 a) acerca da morte da Lagoa Azul, uma reserva hídrica que fazia parte da Orla Sul da cidade:

No sentido Arraial d'Ajuda-Trancoso, em um passado não muito distante, havia um espaço conhecido por/como Lagoa Azul que, por conta de ações insustentáveis no 
turismo, seja com a entrada sem controle de visitantes, seja pela retirada da cobertura vegetal que se localizava próximo às falésias, em especial, na parte de cima, ou pela construção civil, houve a morte desse ambiente natural. No referido espaço, os turistas, além de todos os encantos naturais do local, banhavam-se e se lambuzavam na argila, tida por especialistas e moradores da região, como medicinal. Com o extermínio da lagoa, ficou uma lacuna, um déficit em relação a espaços de exploração do turismo na cidade (SANTANA, 2016 a).

Diante do potencial turístico da cidade e da importância dessa atividade para a região, preservar os recursos hídricos torna-se uma questão de sobrevivência. Para continuar atraindo turistas e gerando emprego e renda, faz-se imprescindível repensar outra lógica de relação com a natureza, em todos os âmbitos da biodiversidade. O turismo, nos moldes atuais na cidade, é insustentável, mas é possível outro turismo, mais sustentável e arvorado no respeito à natureza para o desenvolvimento socioambiental. Nesse sentido, pode-se trazer o que afirma Bruna (2006) ao tecer considerações sobre água e ecoturismo:

Tendo a natureza como sua grande força atrativa, o ecoturismo certamente está relacionado à utilização de água doce, tanto suas fontes, quanto armazenamento em lagos ou represas. A água doce serve também à manutenção da natureza e da própria civilização em seus múltiplos usos (BRUNA, 2006).

A preservação dos rios, além da biodiversidade, pode ser importante para repensar um turismo para além da praia e, dessa forma, dinamizar a economia local, a partir de outros nichos de uso da indústria do turismo. No entanto, esse novo espaço deverá ser usado, como já se mencionou, de forma sustentável, diferente dos primeiros moldes do turismo mono espacial de praia.

A inércia da gestão pública local, ao longo de anos, tem contribuído para acelerar o quadro de desgaste ambiental e, consequentemente, social, haja vista que todo o molde político da região não ultrapassa os limites da economia e da administração tradicional, sem um projeto sólido de gestão socioambiental. No tocante à responsabilidade das gestões municipais no cuidado com a água, é oportuno apresentar o que afirma Barlow (2015):

Os governos têm o direito de reconhecer agora o direito à água e aos saneamentos nas suas próprias constituições ou leis; os direitos não serão inteiramente implementados até que sejam reconhecidos na legislação e constituições de cada país. Alguns países já aprovaram emendas às suas constituições. A África do Sul incluiu a água como um direito humano em sua nova constituição, quando Nelson Mandela formou o seu governo do ANC, e outros países com Etiópia, Equador, Quênia, Bolívia e República Dominicana seguiram o seu exemplo (BARLOW, 2015).

A citação acima é um espaço para interlocução entre o que está acontecendo em 
Porto Seguro e a importância da água para a Terra. É preciso aproveitar a riqueza hídrica que a cidade possui e trabalhar em prol da preservação e manutenção de tais recursos para, inclusive, poder seguir desenvolvendo o turismo. A população, a gestão pública e a indústria do turismo devem pensar soluções em parceria em busca da mitigação ambiental dos rios da Orla Norte, como, também, de outros rios do município.

Todo o quadro de desgaste ambiental dos rios da cidade leva à reflexão no tangente a outras ações e déficits ambientais na cidade e, a partir de tais reflexões, pode-se chegar a outras noções de Barlow (2015) em relação à necessidade de colocar a água no centro da vida e necessidade de honrar Pachamama.

\title{
ALGUNS DADOS SOBRE OS RECURSOS HÍDRICOS DE PORTO SEGURO
}

Porto Seguro possui uma grande riqueza hidrológica e, acerca disso, Veracel (2011) apresenta os seguintes dados:

\begin{abstract}
Porto Seguro destaca-se por uma enorme riqueza de recursos hídricos. Praticamente em todos os pequenos vales do município há nascentes e cursos d'água, e no território do município encontram-se 22 micro bacias hidrográficas. A quase totalidade dos rios e córregos que drenam o município possui vales longos e aprofundamento médio variável, mas normalmente superior a 20 metros, e talvegues de fundo chatos preenchidos por aluviões. O padrão de drenagem observado para os cursos d'água que ocorrem na região dos tabuleiros costeiros é nitidamente dendrítico1 para os tributários de segunda ordem e preferencialmente paralelo para os cursos principais, onde observa-se certo paralelismo entre as calhas fluviais, todos drenando a área em sentido oeste-leste. Este padrão parece ser fruto apenas do controle topográfico imposto pela suave e contínua inclinação dos tabuleiros em direção leste (VERACEL, 2011).
\end{abstract}

A água é um recurso natural importantíssimo para a vida e, acerca disso, Scarpa e Soares (2012) pontuam o seguinte: "O aumento da intensidade e da frequência de fenômenos climáticos extremos, a poluição e o desperdício estão colocando em risco a segurança hídrica em nosso país. Precisamos cuidar melhor de nossa água, praticando um consumo consciente".

Conforme dados do Plano Municipal de Conservação e Recuperação da Mata Atlântica de Porto Seguro - PMMA, fazem parte do município os seguintes rios: Jardim, dos Mangues, Mundaí, São Francisco, Da Vila, Buranhém, Mucugê, Pitinga, Lagoa Azul, Taípe, da Barra, Córrego do Entulho, Trancoso, Verde, Nova Itapororoca, Itaquena, Dos Frades, Setiquara, 
Pratiaçu, Jurema, Caraíva e Corumbau.

Figura 1. Imagem retirada do documento: Plano Municipal de Conservação e Recuperação da Mata Atlântica de Porto Seguro. Rede hidrográfica do município de Porto Seguro

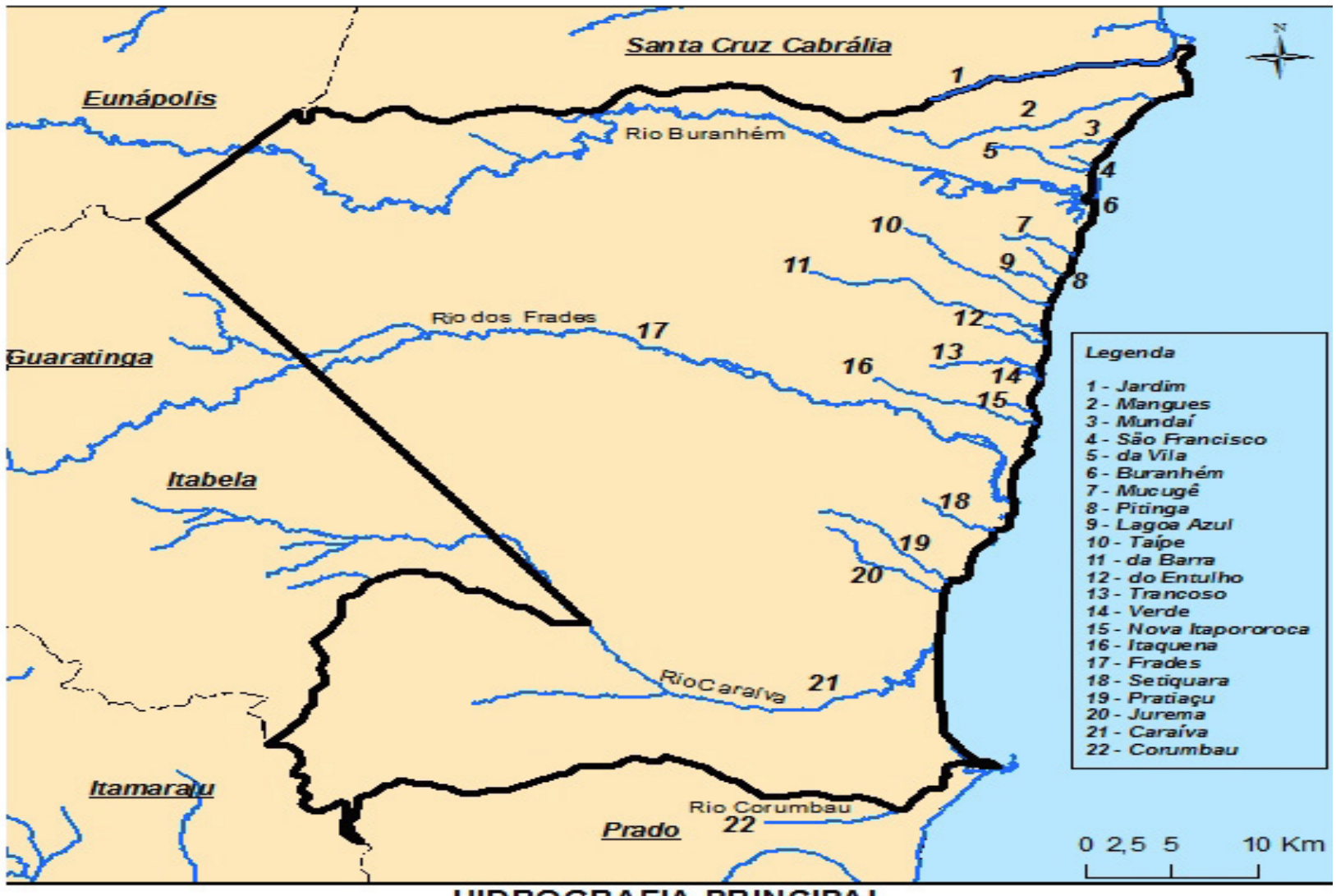

Fonte: Adaptado de RIBEIRO et al., (2010).

Segundo o documento PMMA (2014), esses rios, riachos e córregos configuram-se da seguinte forma:

- Rio Jardim - localiza-se na divisa com o município vizinho, Santa Cruz Cabrália. A nascente é encontrada no interior da RPPN Veracel. Seu trecho inicial está em bom estado de conservação, mas que existem trechos degradados de áreas ciliares que merecem trabalhos de restauração florestal.

- Rio dos Mangues - esse rio abastece o núcleo urbano de Porto Seguro e a orla norte da cidade. Algumas de suas nascentes localizam-se na Estação Pau-Brasil, da CEPLAC e outra parte na RPPN Veracel. Conforme o documento PMMA, algumas iniciativas de 
restauração de suas matas ciliares foram conduzidas pela Embasa e pelo Movimento de Defesa de Porto Seguro.

- Rio Mundaí - este rio é formado por pequenos cursos d'água oriundos dos platôs e da região praiana. Sua foz se dá na praia de Mundaí.

- Rio São Francisco - micro bacia hidrográfica; desemboca na entrada do Outeiro da Glória, na área do Memorial da "Epopeia do Descobrimento".

- Rio da Vila - é um pequeno rio que nasce às margens da BR 367, nos limites do município e desemboca na praia de Itacimirim.

- Rio Buranhém - é um rio federal que corre paralelamente à área urbana central do município de Porto Seguro. É, sem dúvida, o maior rio do município e suas nascentes estão localizadas no estado de Minas Gerais. Este rio tem grande influência na qualidade das praias do município, pois sua foz é na região central da área urbana de Porto Seguro e verte para as praias do litoral norte.

- Rio Mucugê - este rio corta a malha urbana do distrito de Arraial D’Ajuda e é um dos rios mais poluídos da costa de Porto Seguro por receber esgoto doméstico diretamente em seu leito. O referido rio apresenta problemas de desmatamento das margens, ocupação urbana irregular, poluição e esgoto a céu aberto, além de depósito de lixo urbano.

- Rio Pitinga - rio situado no distrito de Arraial D’Ajuda. É ainda bem conservado e possui águas claras em seu leito. Deságua na praia de Pitinga e mantém a boa qualidade daquele balneário.

- Rio Lagoa Azul - é um pequeno rio intermitente, cujas cabeceiras são compostas de vegetação de mussunungas e campinaranas e solo bastante arenoso. No período chuvoso, esse rio forma uma cachoeira próxima à praia da Lagoa Azul ${ }^{2}$. Também é responsável pela formação da lagoa de mesmo nome, ponto turístico do litoral de Porto Seguro.

- Rio Taípe - é um dos rios mais conservados da costa porto-segurense. Ele nasce no Parque Nacional do Pau Brasil e atravessa várias RPPNs, o que garante suas águas claras. Em sua foz há um manguezal expressivo.

${ }^{2}$ O PMMA não faz referência aos déficits ambientais na Lagoa Azul, mas é importante ressaltar que este espaço foi degradado e já não é mais um espaço utilizado pelo turismo na região. 
- Rio da Barra - também está bastante conservado. Tem sua nascente dentro da área do Parque Nacional do Pau Brasil e passa pela RPPN Rio do Brasil. Possui águas claras e em sua foz existe uma significativa área de manguezal.

- Rio/Córrego do Entulho - é um córrego bem conservado.

- Rio Trancoso - é um rio perene, com bom volume de água, que deságua no distrito de Trancoso. Também atravessa RPPNs após nascer no Parque Nacional do Pau Brasil.

- Rio Verde - micro bacia presente no distrito de Trancoso, deságua na praia do mesmo nome. O referido rio passa em áreas urbanas e requer ações de conservação e despoluição.

- Rio Nova Itapororoca - está localizado na estrada da praia de Itaquena, onde deságua. Seu trecho final foi formado recentemente com o desvio provocado por um barramento, e hoje corre em área de restinga.

- Rio Itaquena - é um pequeno curso d'água cuja microbacia está inserida em um imóvel rural (Fazenda Itaquena) e deságua em praia do mesmo nome.

- Rio dos Frades - atravessa a área urbana de Guaratinga e Itabela e deságua na praia de Itaquena. No seu trecho final, passa pelo Refúgio de Vida Silvestre do Rio dos Frades.

- Rio Setiquara - é um pequeno curso d'água, de águas claras, que passa junto ao distrito de Itaporanga.

- Rio Pratiaçu - este rio possui águas claras e cristalinas, corre em áreas bem conservadas de Mata Atlântica e deságua na praia do Espelho.

- Rio Jurema - é um pequeno rio localizado no sul do distrito de Itaporanga, apresenta boa qualidade de água.

- Rio Caraíva - é um dos maiores rios do município, com suas nascentes situadas no município de Itabela. Tem grande importância para pesca e turismo local, desembocando no distrito de Caraíva, que confere uma beleza especial à localidade.

- Rio Corumbau - é um rio localizado na divisa dos municípios de Porto Seguro e Prado. Parte de suas margens está dentro do Parque Nacional Histórico de Monte Pascoal. Tem grande importância para pesca regional. 


\section{A SITUAÇÃo AMBIENTAL DOS RIOS DA ORLA NORTE DA CIDADE}

O Rio Buranhém desponta como o Rio que está no limite entre o perímetro da Orla Norte e da Orla Sul, portanto, um divisor. Na Orla Norte, localizam-se os seguintes rios: Rio da Vila, Rio São Francisco, Rio Mundaí, Rio dos Mangues e Rio Jardim, todos, em algum estado de déficit ambiental.

Segundo Brasil (2014):

Porto Seguro faz parte do sistema de abastecimento de água e coleta de esgoto da "costa", que compreende a sede de Porto Seguro, as sedes dos distritos de Arraial d'Ajuda e Trancoso, a reserva de Coroa Vermelha e os municípios de Santa Cruz Cabrália e Belmonte. Esse sistema tem 21 mil ligações de esgoto e 27 mil de água. A Embasa aponta um índice de cobertura de $89,6 \%$ no sistema de abastecimento de água e de $87 \%$ no sistema de esgotamento sanitário na cidade de Porto Seguro (Rafael A. B. de Almeida, com.pess., 2014) A sede do município é abastecida pelo sistema de água do rio dos Mangues, que produz diariamente $9.703 \mathrm{~m}^{3}$. A estação de tratamento de água (ETA) está localizada junto ao rio dos Mangues, na orla norte de Porto Seguro. A estação de tratamento de esgoto (ETE) da sede municipal está localizada no bairro Vila Vitória e existem captações de água a jusante, o que indica a qualidade do tratamento, segundo a Embasa. O sistema conta com cerca de 40 estações elevatórias e, após o tratamento, o emissário é o rio Buranhém. A situação do lixo é bastante complicada, tendo em vista que a cidade apresenta uma população urbana de grande porte e uma população flutuante nas temporadas que incrementa significativamente o volume de resíduos sólidos produzidos. A prefeitura realiza coleta domiciliar nas áreas urbanas, porém não consegue fornecer descarte adequado aos resíduos e joga estes num lixão localizado às margens da BR-367.

Nos últimos artigos em torno das insustentabilidades e caminhos possíveis para um turismo sustentável em Porto Seguro, Santana (2016 b) discorre acerca dos principais déficits socioambientais originados a partir das relações predatórias paradoxais da indústria do turismo com o capital natural que propicia o desenvolvimento das atividades turísticas na região, pontuando o seguinte no que concerne aos recursos hídricos da cidade:

Há pontos estratégicos para o turismo na cidade. Começando pelo centro, há a Passarela do Álcool, onde, diariamente, são armadas barracas para vendas de alimentos, bebidas e artesanatos locais, com a circulação de milhares de pessoas. Esse ponto turístico também é o local para a realização das festas mais importantes da cidade, com bandas e circulação de trios elétricos. O problema é que essa parte está localizada às margens do Rio Buranhém, que desagua no mar, e, após as festividades, são visíveis os impactos ambientais com a presença de resíduos sólidos como garrafas plásticas, de vidro e de metal no leito do rio. $\mathrm{Na}$ Orla Norte há grandes empreendimentos como barracas e hotéis com festas na praia, em que é possível verificar o acúmulo de resíduos sólidos e líquidos. Além desses problemas, vários rios e riachos desse perímetro estão contaminados com o despejo de esgotos e outros resíduos. Para piorar a situação, novos empreendimentos e condomínios são construídos nessa parte da orla a cada ano. Do centro de Porto Seguro para o Arraial d'Ajuda (outro ponto muito importante para o turismo) há a travessia de balsa pelo Rio Buranhém e tais embarcações são abastecidas às margens do próprio rio, o que demanda cuidado e política sólida de fiscalização ambiental, pois há o risco de 
contaminação da água com o vazamento de óleo. Do outro lado, há engarrafamentos na Estrada do Arraial até o Centro do Distrito e isso provoca, além dos ruídos que perturbam aves e outros animais da fauna local, poluição com o lançamento de CO2. Saindo do Arraial, há o turismo ainda mais luxuoso no Distrito de Trancoso e, nesse espaço, a natureza passa por um acelerado processo de desgaste, em que grandes hotéis são construídos e o distrito, por conta do sucesso econômico advindo do turismo, atrai um contingente de pessoas de outras partes do município e de outras cidades da região, ocasionando o crescimento urbano e populacional desordenado com o surgimento de bairros sem condições sanitário-ambientais (SANTANA 2016 b).

Nessa oportunidade, serão apresentados alguns dos problemas que afetam os rios do perímetro da Orla Norte, compreendido entre o Rio da Vila e o Rio dos Mangues, partindo-se do pressuposto de que esses cursos de água são atrativos naturais que embelezam a cidade, fazem parte da biodiversidade natural-ambiental, e que, portanto, poderiam ser utilizados, de forma sustentável, para atrair ainda mais turistas para a região e possibilitar o desenvolvimento socioambiental.

No tangente à situação ambiental dos rios da Orla Norte, pode-se encontrar intersecção entre poluição, desgaste ambiental e turismo, mas, nesse caso específico, o principal elemento desencadeador do problema reside na relação cultural dos habitantes que vivem no município e no comportamento de algumas empresas que atuam na cidade.

Dentre os cursos de água no perímetro da Orla Norte, talvez, o que esteja em situação mais degradante seja o Rio da Vila. Acerca desse rio, há relatos e matérias em jornais da cidade, como o Jornal do Sol, que trazem à tona denúncias no tocante a crimes ambientais contra o rio, como o que ocorreu no ano de 2015.

Conforme pontuou o Jornal do Sol, em matéria publicada em 26 de março de 2015, "Esgoto da Embasa vaza para o Rio da Vila", o histórico Rio da Vila, importante fonte de água limpa em Porto Seguro, continua sua crônica de uma morte anunciada. Mais uma vez, ele foi agredido com o vazamento, dia 23/03/15, por uma grande quantidade de esgoto da Embasa. De acordo o secretário municipal de Meio Ambiente da cidade, a Secretaria Municipal do Meio Ambiente tomou todas as medidas cabíveis, incluindo a aplicação de multa de R\$300 mil a Embasa e o encaminhamento de processo para o Ministério Público.

Ainda conforme o referido periódico, na mesma matéria, pontuou-se que a Embasa disse em nota que o vazamento havia ocorrido devido à falta de energia elétrica e que para o secretário municipal do Meio Ambiente, o argumento não justificava esse tipo de falha. Conforme o secretário, "A Embasa cobra caro pelo serviço e $80 \%$ da conta de água são relativos à taxa de esgoto. A empresa precisa rever seus conceitos de operação em todas as subestações, que devem possuir 
geradores e bombas reservas".

Abaixo, aparece uma foto do Rio da Vila, publicada na matéria do referido jornal:

Figura 2. Rio da Vila

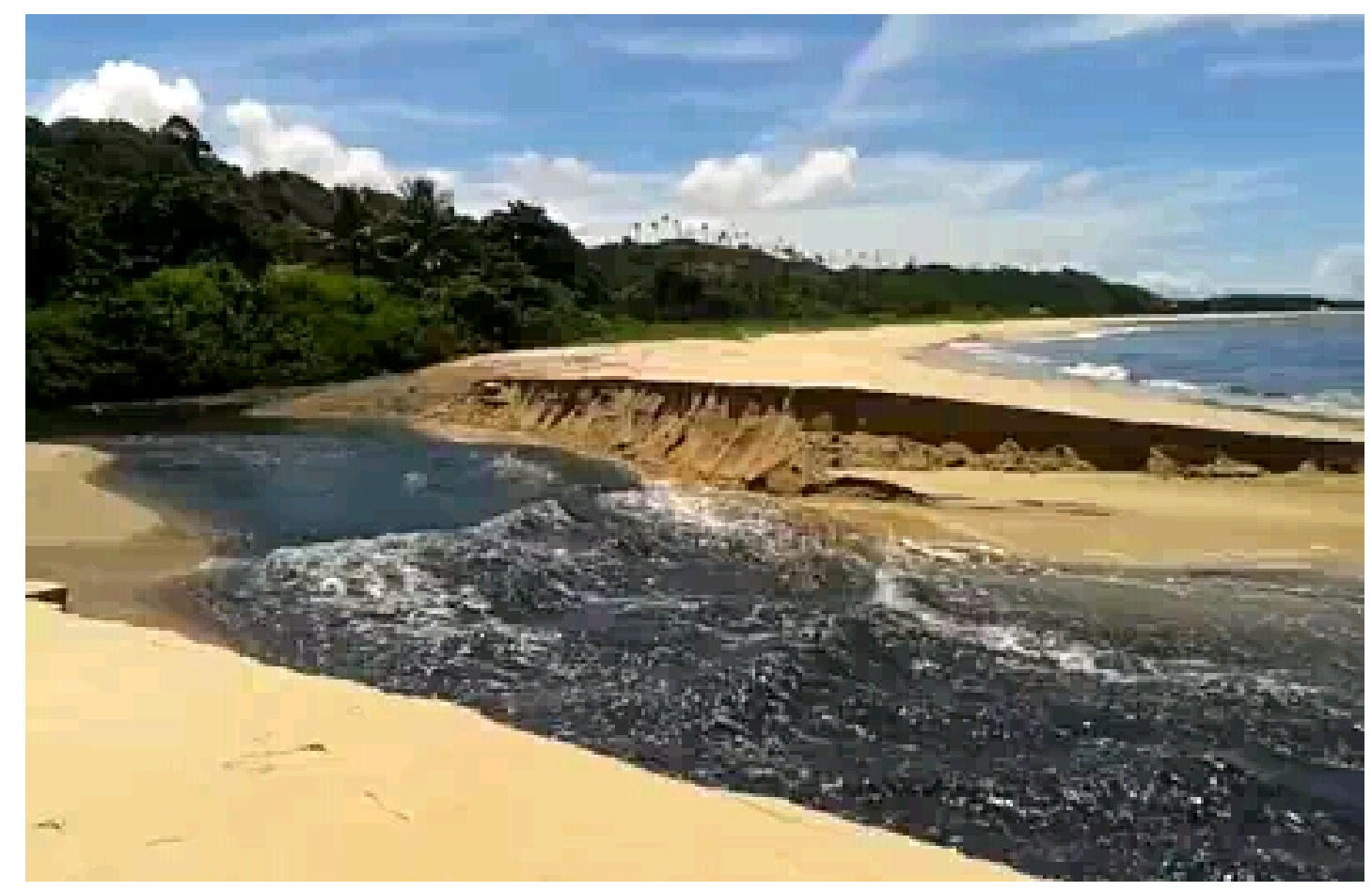

Fonte: Jornal do Sol, 2015.

Assim como a matéria do Jornal do Sol em 2015, há outras matérias em outros periódicos, do mesmo ano, de anos anteriores e até de 2016, acerca da situação ambiental de rios da região, como o Buranhém, por exemplo, que não está no perímetro aqui analisado, mas que é o principal rio que passa pela cidade e que vem sofrendo, ao longo de anos, um grave processo de poluição e degradação ambiental em geral.

Além da situação ambiental do Rio da Vila, para a elaboração de projeto de pesquisa, por conta de uma seleção de mestrado que participaria, ao longo de 2014 e 2015, in loco, verifiquei nos Rios São Francisco, Mundaí e dos Mangues a presença de resíduos sólidos e líquidos poluidores. Pese a este fato, a questão do mau cheiro que, em alguns dias, durante a pesquisa de campo, pode-se sentir. O mau cheiro, talvez, se dê devido ao lançamento de esgotos domésticos e de outros tipos, por conta da urbanização descontrolada e desordenada da cidade ao longo de parte do percurso dos rios, o que não foi possível corroborar o fato, haja vista que não ocorreu a análise de qualidade da água, mas a questão da degradação é bastante visível nos referidos espaços. 
Em todos os rios citados, pode-se verificar a presença, dentro e na margem, de garrafas pets, litros de vidro, latas de cerveja, cadeiras plásticas, sacolas plásticas, pedaços de móveis de madeira e de metal, sapatos, suportes plásticos de TVs antigas, roupas, dentre outros resíduos sólidos, situação que traduz a relação insustentável da sociedade porto-segurense com os recursos hídricos da cidade.

Para pensar essa relação insustentável da sociedade com o capital hídrico, é possível entrelaçar esse problema com o que pontua Queiroz (2006), quando este afirma que no entendimento dos antropólogos, o ambiente em que vivemos é duplo, a um só tempo natural e cultural, sem que talvez se possa afirmar em qual desses domínios as nossas raízes são mais profundas.

Silva e Fernandes (2005), no artigo “Turismo, desenvolvimento local e pobreza no município de Porto Seguro - BA" ao apresentarem uma crítica ao processo de ocupação de Porto Seguro, de forma desordenada, a partir do turismo de massa, tocam na questão dos rios quando pontuam o seguinte: além da destruição dos ecossistemas, o processo de ocupação alterou grande parte das paisagens mais próximas a Porto Seguro e Santa Cruz Cabrália, comprometendo irreversivelmente a sua beleza e atratividade. O crescimento populacional exponencial e a pressão demográfica sazonal dos turistas vêm gerando graves problemas de saneamento, ocasionando inúmeros depósitos irregulares de lixo e a poluição dos lençóis freáticos, cursos de água, e consequentemente, das praias mais frequentadas pelos banhistas.

\section{ALGUMAS CONSIDERAÇÕES FINAIS}

Constata-se que a situação dos rios no perímetro da Orla Norte de Porto Seguro não é nada regular e que a sociedade e a gestão pública municipal fecham os olhos para a situação. A sociedade tem sua parcela de culpa pelo depósito de resíduos e pela retirada da cobertura vegetal às margens dos cursos de água para a construção de condomínios e casas, em geral, e a gestão pública municipal, pela situação de inércia, descaso e inoperância, pois diante da degradação ambiental nos espaços aqui apresentados, deveria desenvolver planos de recuperação dos cursos de água no referido perímetro da orla do município, mas pouco ou nada fora feito. Além disso, faltam políticas públicas eficientes de educação ambiental na cidade para a sociedade, pois de nada adiantará recuperar os rios, se não houver mudança na arquitetura mental societária porto-segurense na relação com o capital natural hídrico. 
A degradação desses rios não é recente, pois é resultante de um processo histórico. A inércia da gestão pública em torno de projetos de mitigação ambiental que possam solucionar o problema não é somente da gestão pública atual, mas de vários gestores municipais ao longo de anos.

Enfim, essa história de descaso municipal em torno dos rios do Perímetro da Orla Norte e em outras partes do município somente mudará quando a cidade tomar consciência dos prejuízos ambientais a partir da possível morte dos rios. Diante dessa consciência, surgirão novos atores cônscios socioambientais e, dessa forma, haverá a cobrança de uma visão socioambiental sustentável das gestões públicas locais, que levem em conta um projeto de governo de respeito à biodiversidade ambiental e desenvolvam políticas de justiça socioambiental.

\section{REFERÊNCIAS}

BARLOW, Maude. Água, futuro azul. Como proteger a água potável para o futuro das pessoas e do planeta para sempre. São Paulo: M.ebooks do Brasil Editora Ltda 2015.

BOFF, Leonardo. Ecologia: grito da Terra, grito dos pobres: dignidade e direitos da Mãe Terra. Petrópolis, RJ: Vozes, 2015.

BRASIL. Plano Municipal de Conservação e Recuperação da Mata Atlântica de Porto Seguro. Porto Seguro, 2014.

BRUNA, Gilda Collet. Água e ecoturismo. In REBOUÇAS, Aldo da Cunha et al. Águas doces no Brasil: capital ecológico, uso e conservação. São Paulo: Escrituras Editora, 2006.

Esgoto da Embasa vaza para o Rio da Vila. Disponível em: http://www.jornaldosol.com.br/index.php/meioambiente/313-esgoto-da-embasa-vaza-para-o-rio-da-vila. Acesso em 10 de julho de 2016.

MILLER, Jr. TYLER, G. Ciência Ambiental. São Paulo: Cengage Learning, 2012.

QUEIROZ, Renato da Silva. Caminhos que andam: os rios e a cultura brasileira. In REBOUÇAS, Aldo da Cunha. BRAGA, Benedito e TUNDISI. José Galizia. Águas doces no Brasil: capital ecológico, uso e conservação. São Paulo: Escrituras Editora, 2006.

SANTANA, Elissandro dos Santos. Caminhos possíveis para um turismo sustentável em Porto Seguro, Bahia. Revista Ecodebate, Rio de Janeiro, ISSN 2446-9394, nº 2.545, 10/06/2016. a.

SANTANA, Elissandro dos Santos. Sugestão de pesquisa em torno das ações insustentáveis e déficits socioambientais no turismo de Porto Seguro-Bahia. Paripiranga: Revista Letrando ISSN 2317-0735, 2016. b.

SCARPA, Fabiano. SOARES, Ana Paula. Novo clima, novo ambiente. Água limpa para todos. São José dos Campos, SP: INPE, 2012.

SILVA, Marcelo Santana. FERNANDES, Fábio Matos. Turismo, desenvolvimento local e pobreza no município de Porto Seguro - BA. Revista Espaço Acadêmico, N. 51. Agosto/2005, Mensal, ISSN 1519-6186.

TRIGUEIRO, André. Mundo Sustentável 2. Novos rumos para um planeta em crise. São Paulo: Globo, 2012.

VERACEL CELULOSE. 2011. EIA/RIMA - Estudo de Impacto Ambiental - Relatório do Meio Físico. 538 p. (Não publicado). In BRASIL. Plano Municipal de Conservação e Recuperação da Mata Atlântica de Porto Seguro. Porto Seguro, 2014. 